\title{
Utilizing o-Quinone Methide Chemistry: Synthesis of
}

\section{$d_{9}$-Ivacaftor}

Adam R. Looker, ${ }^{+, *}$ Nathan Wilde, ${ }^{\#}$ Michael P. Ryan, ${ }^{\ddagger}$ Stefanie Roeper, ${ }^{\dagger}$ Zhifeng Ye, ${ }^{\S}$ Bérénice Lewandowski, $^{\dagger}$

Process Chemistry and Engineering \& Materials Sciences, Vertex Pharmaceuticals Incorporated, 50 Northern Avenue, Boston, Massachusetts 02210

*Author for correspondence. E-mail: adam_looker@vrtx.com

${ }^{\dagger}$ Process Chemistry, Vertex Pharmaceuticals, Inc. Boston, MA

\# Process Chemistry, Vertex Pharmaceuticals, Inc. San Diego, CA

Engineering \& Materials Sciences, Vertex Pharmaceuticals, Inc. Boston, MA

$\S$ Technical Operations, Vertex Pharmaceuticals, Inc. Boston, MA

\section{Supporting Information}

\section{Table of Contents}

1. NMR spectra

2-9

2. HRMS spectra

$10-11$ 


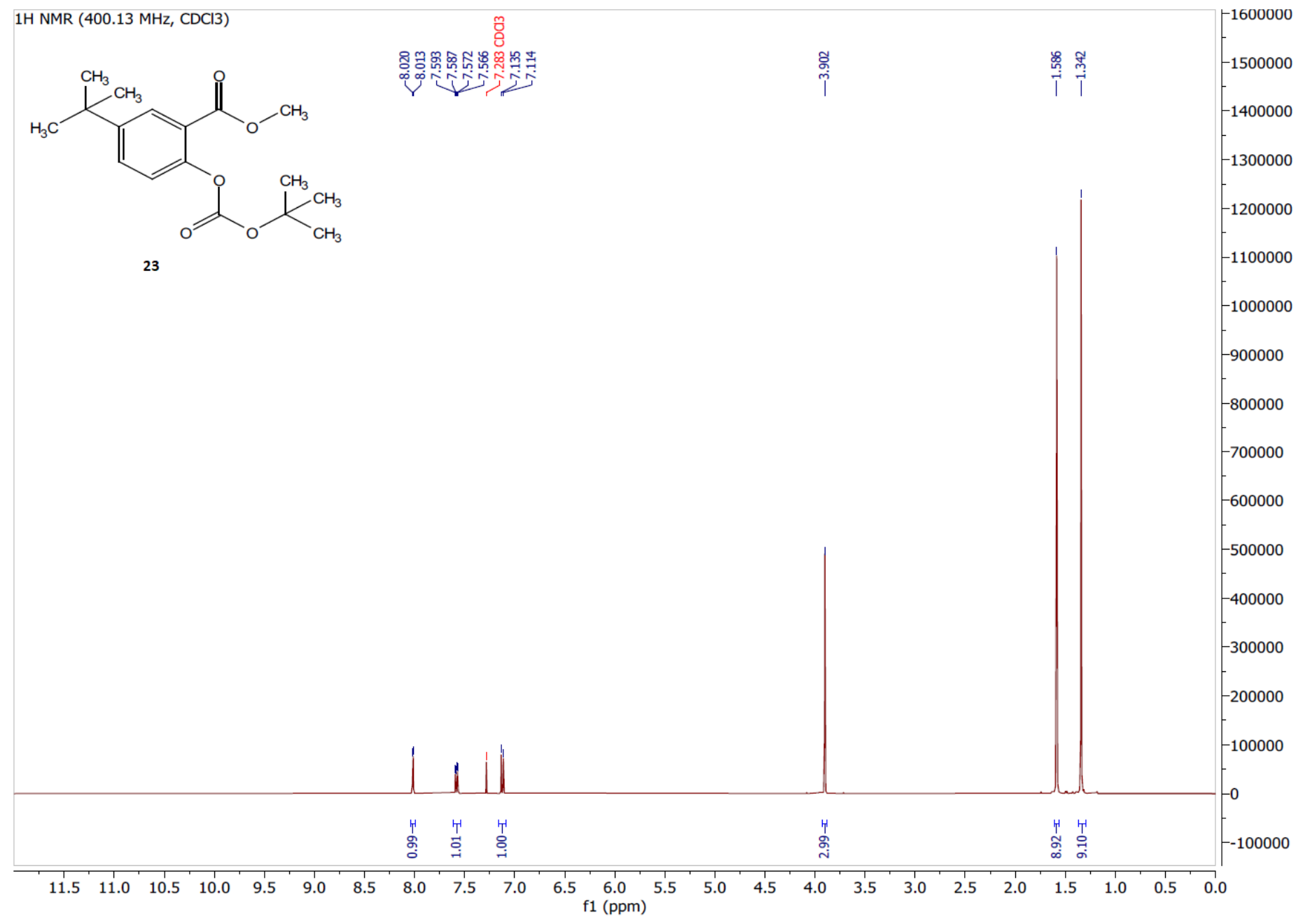




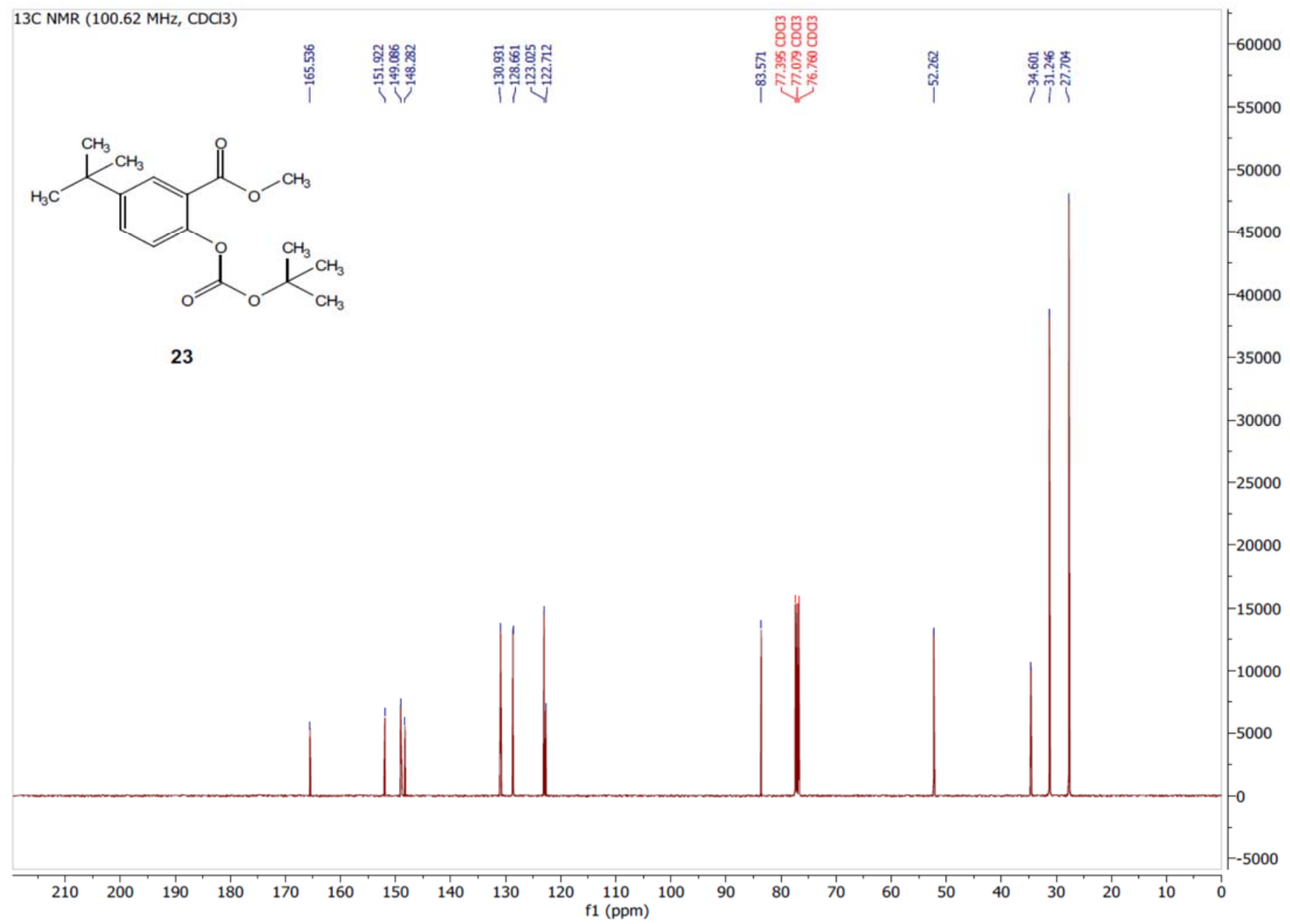




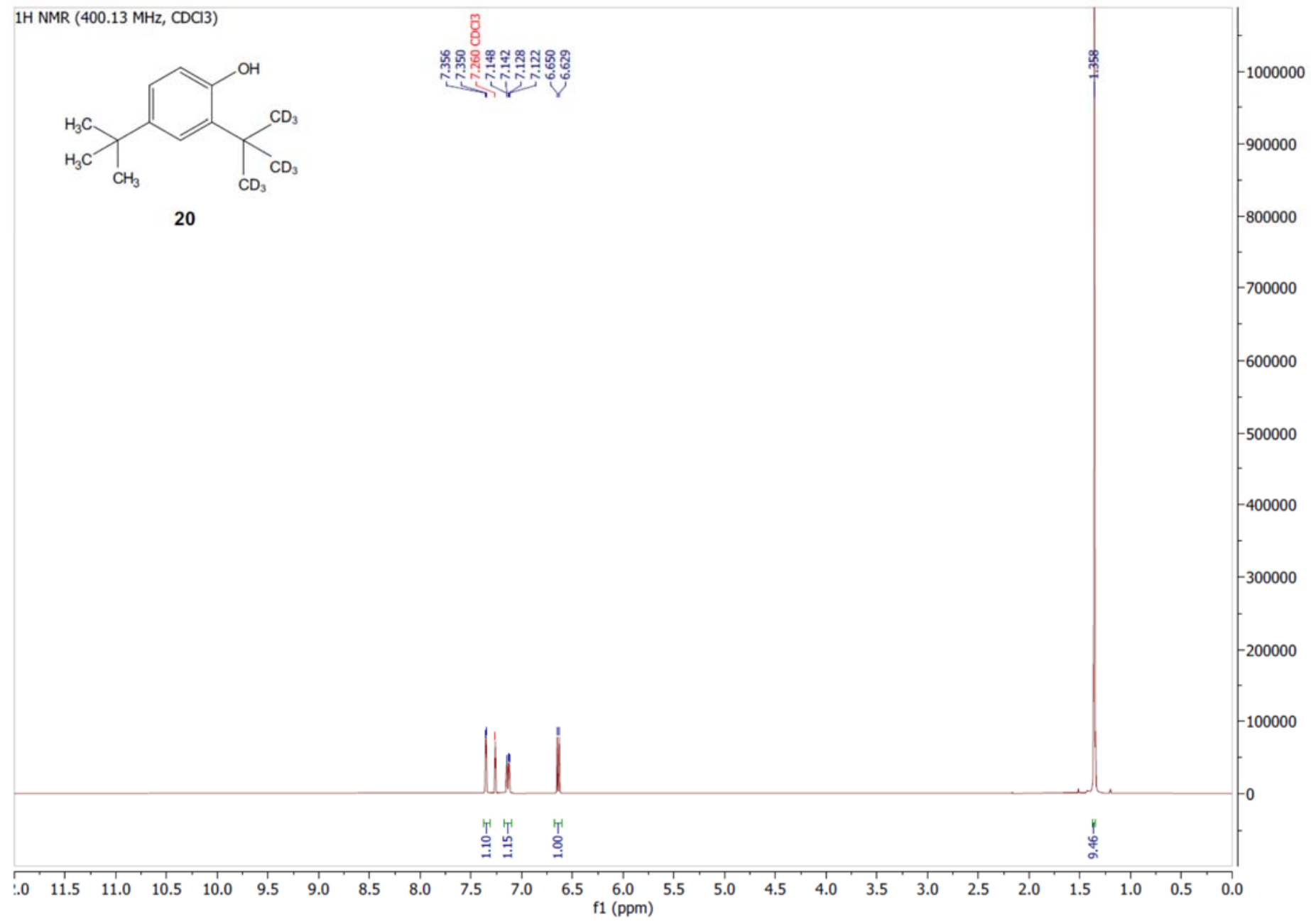




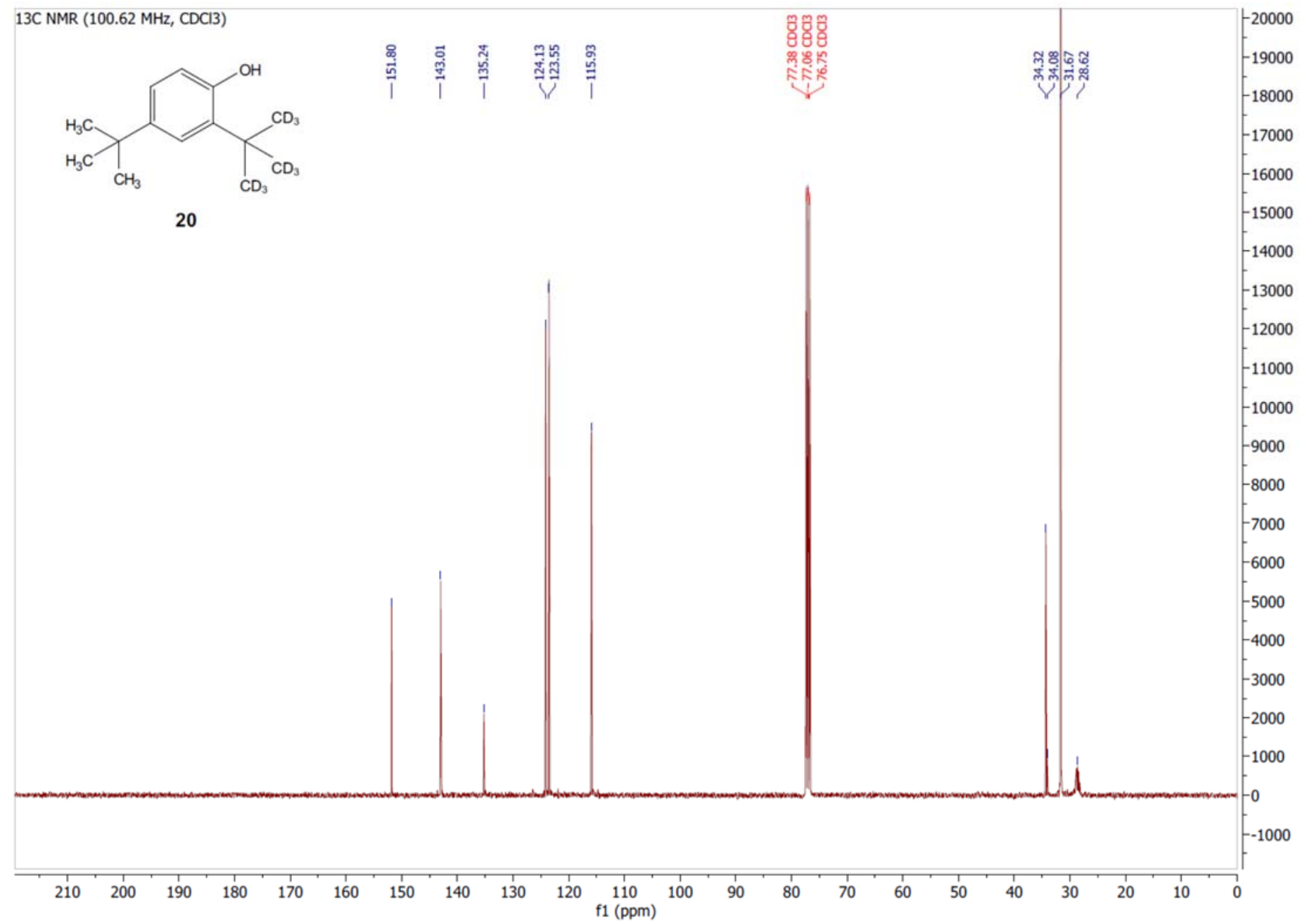




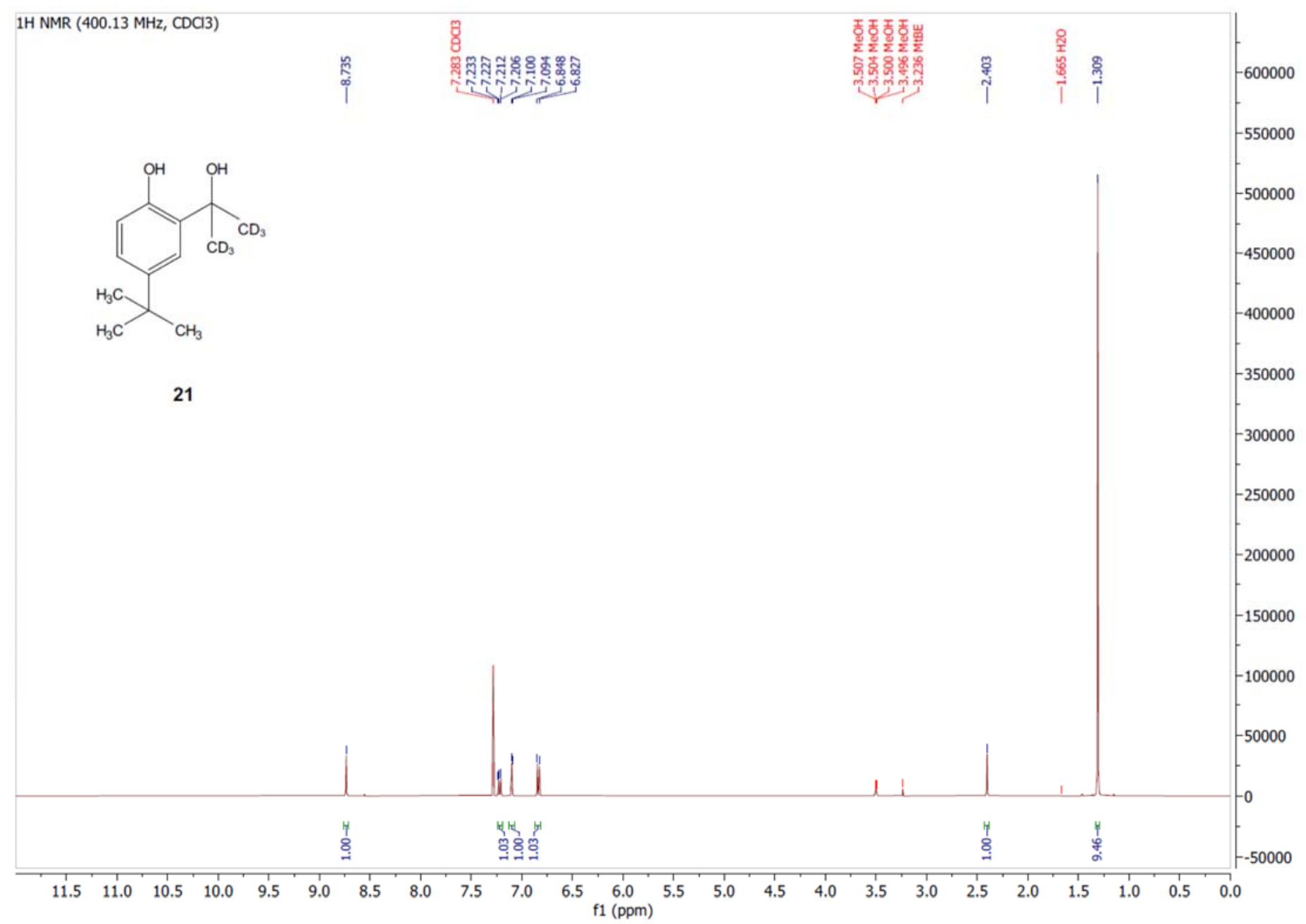




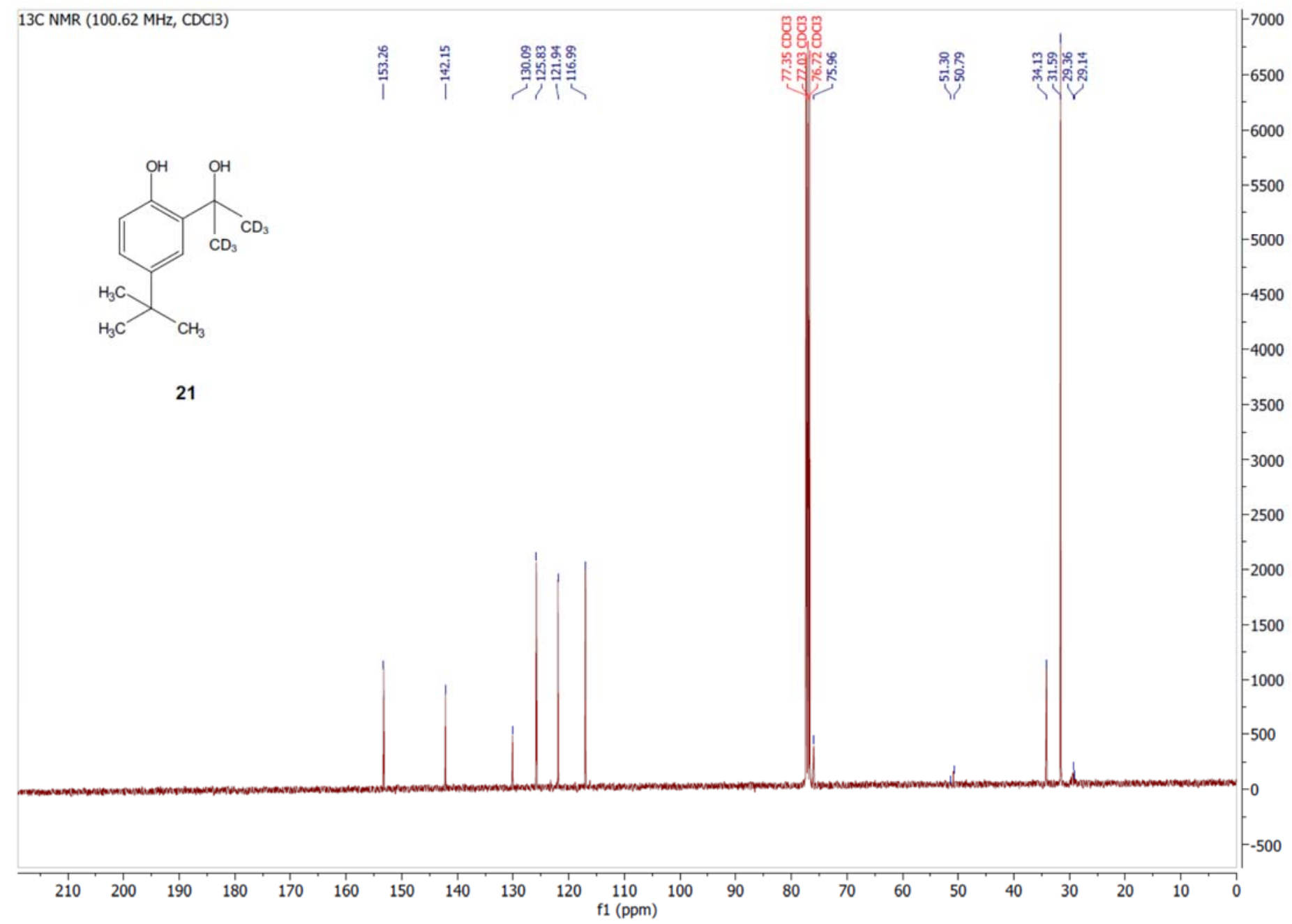




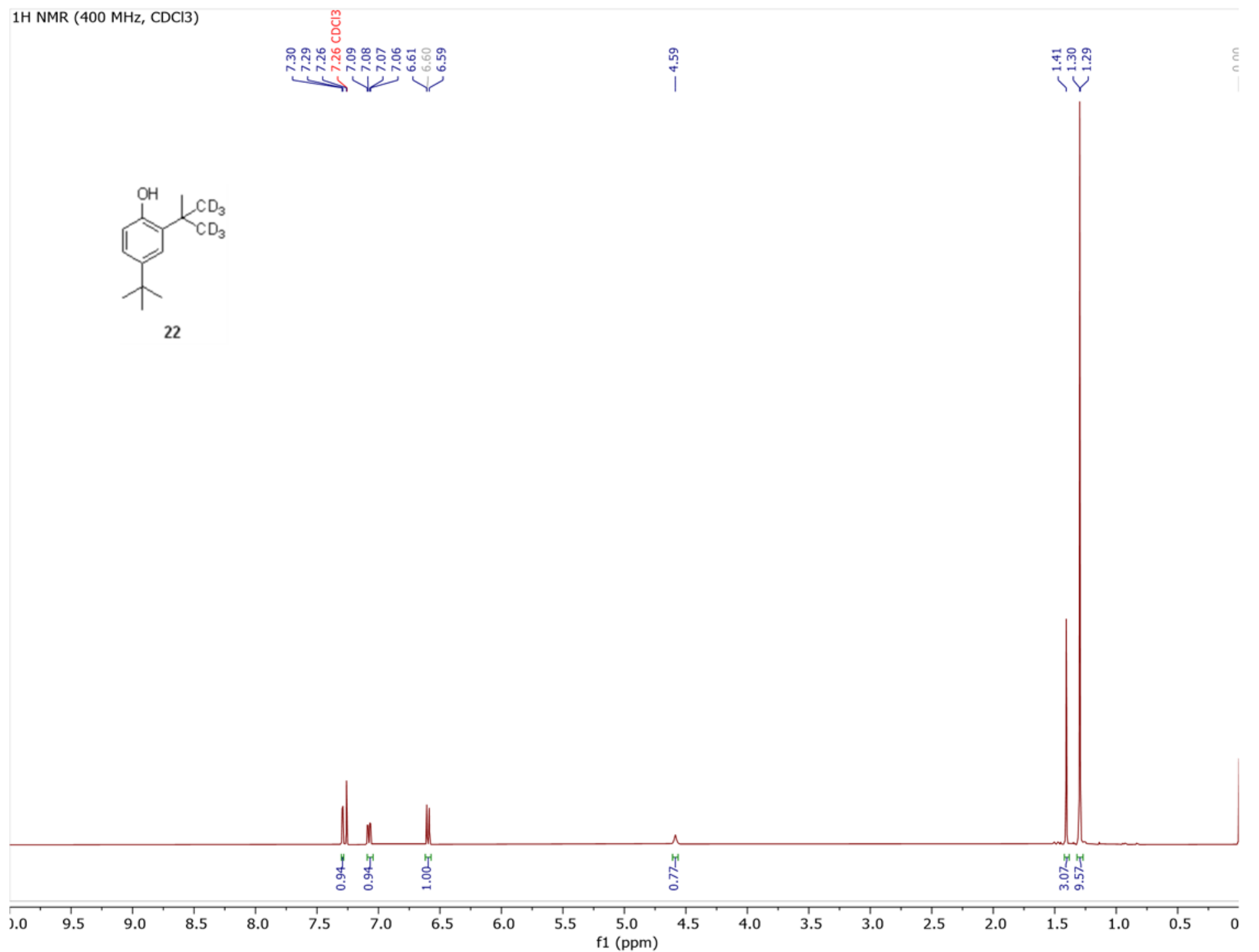




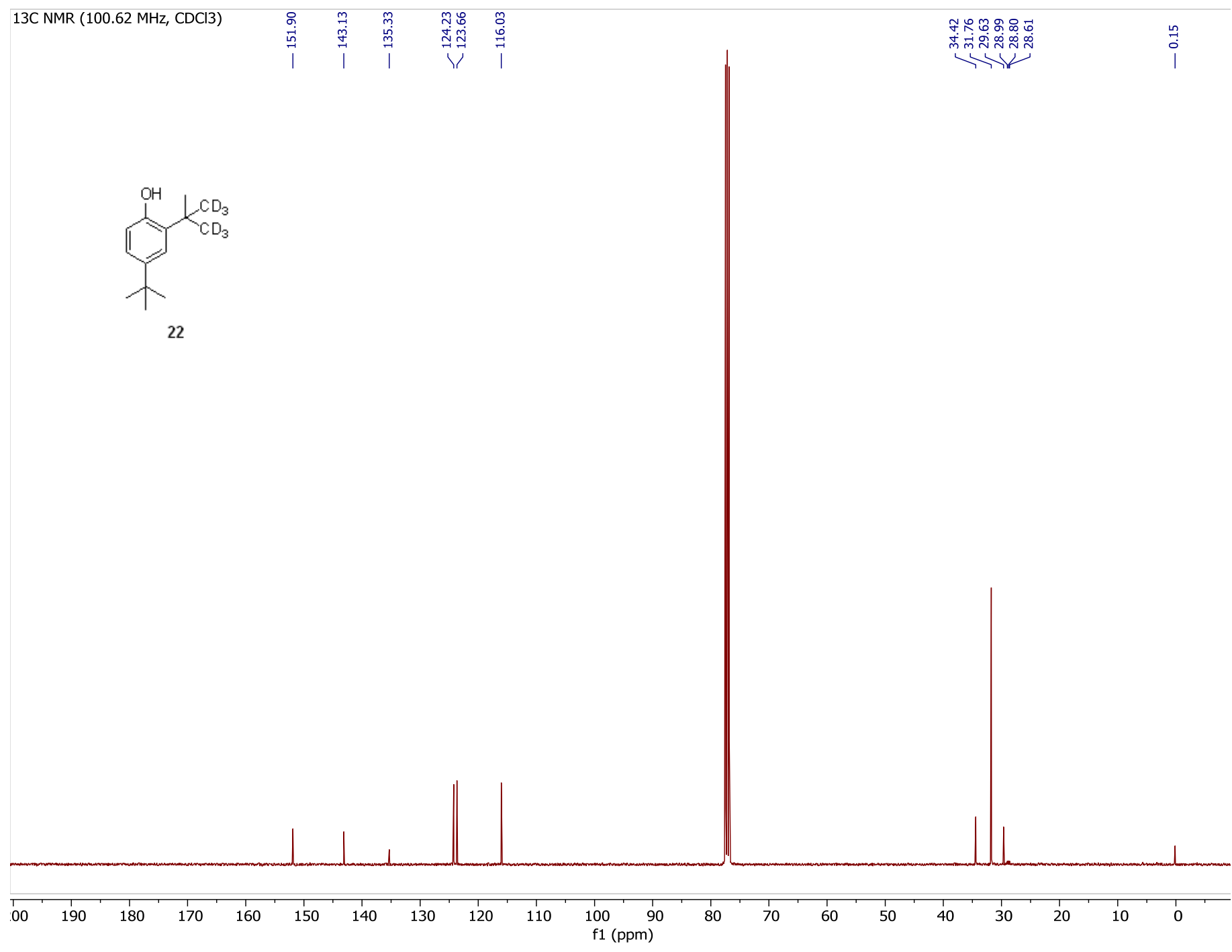




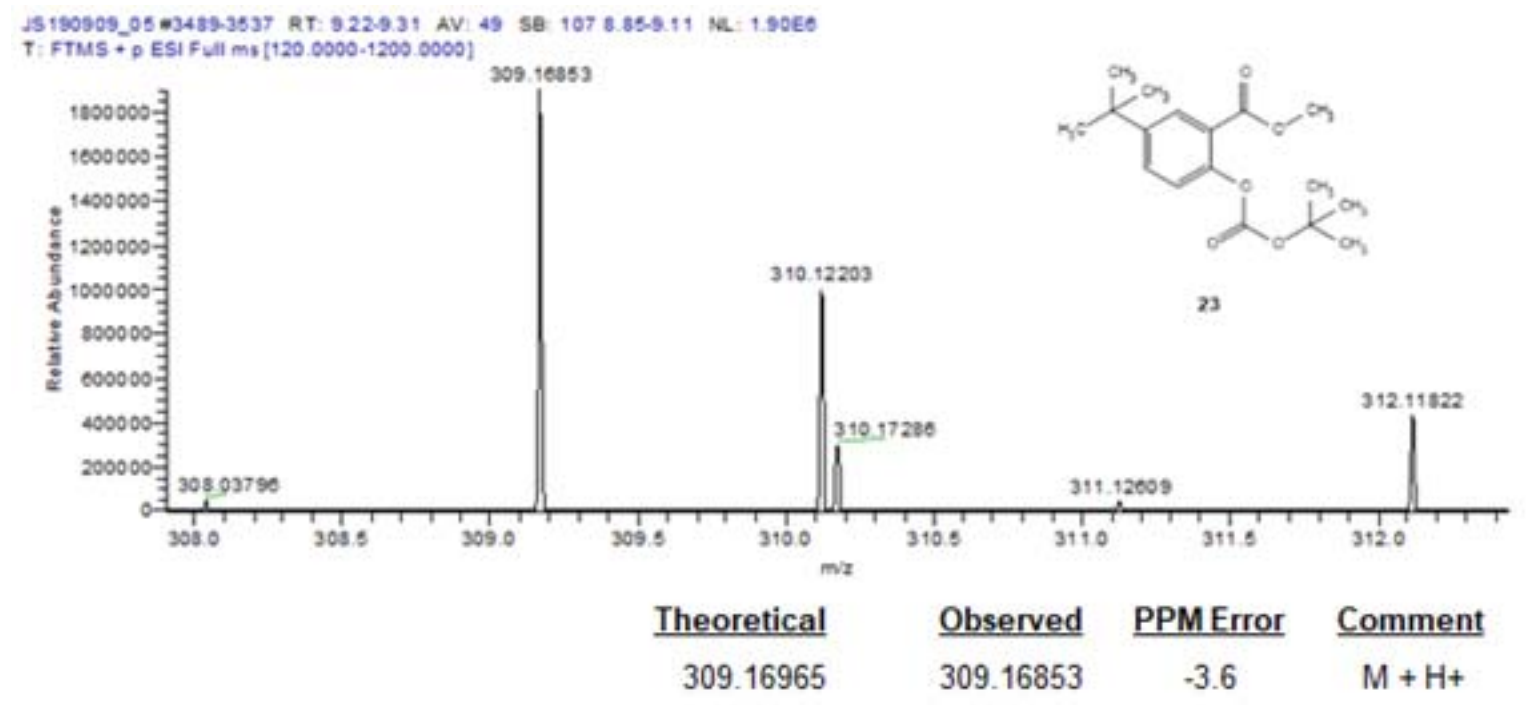

JS190909_04 $43588-3633$ RT: $9.37-9.45$ AV: 46 S8: $1078.78-9.04$ NL: $1.07 E 7$ T: FTMS + p ESI Full ms [120.0000-1200.0000]

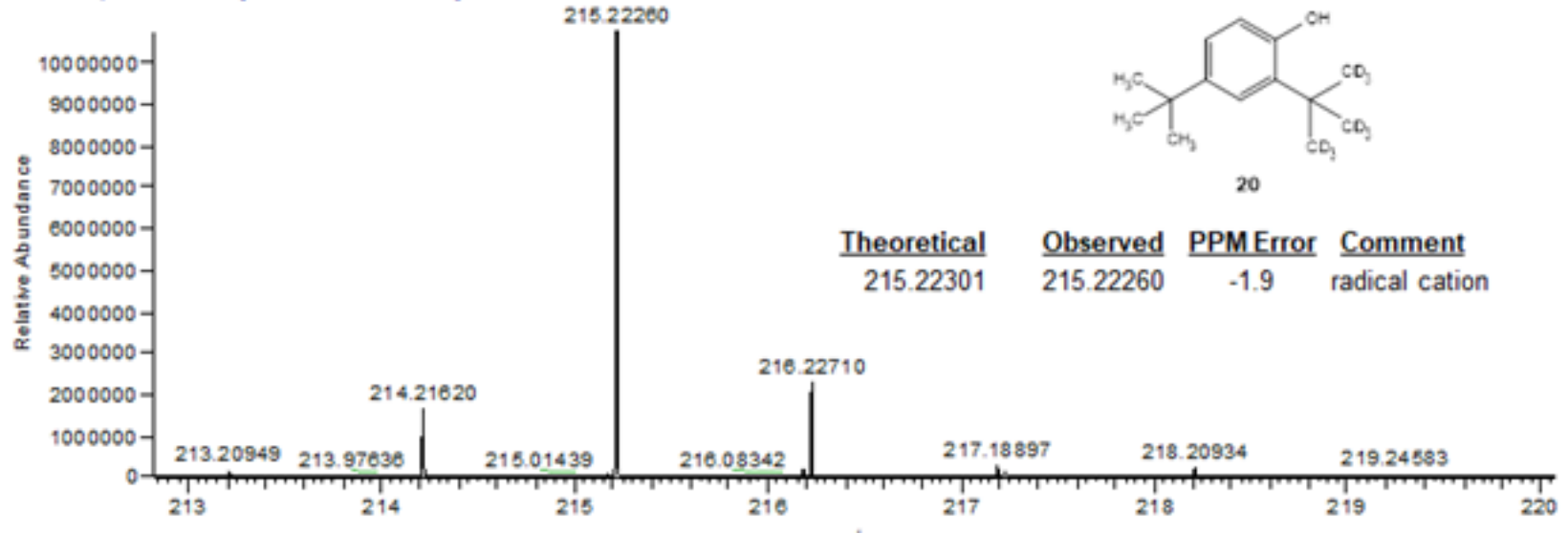



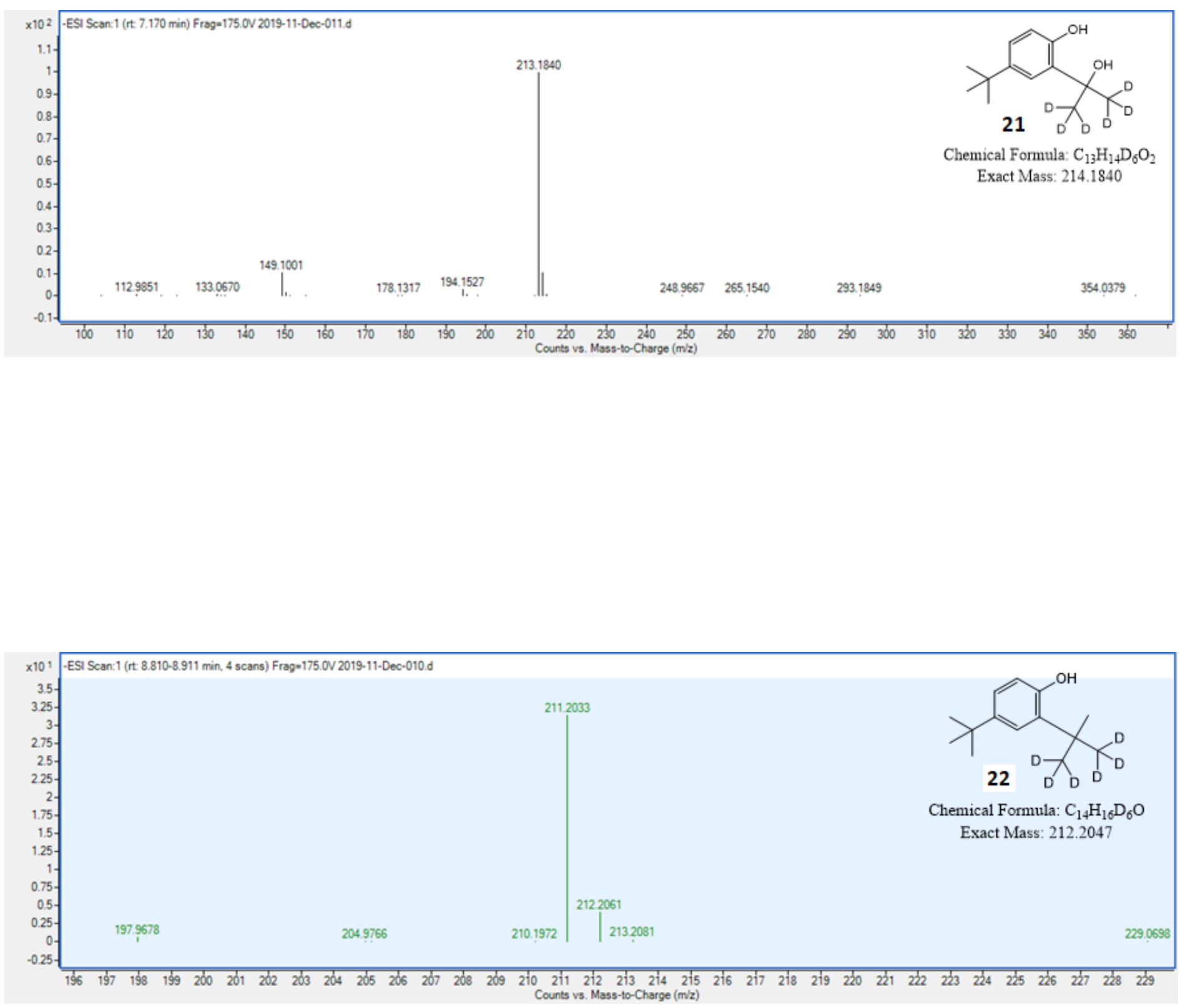